\title{
Research on the Information Transmission of Education Management in Newly Established Local Undergraduate Colleges
}

\author{
Sui yong, Qin bo \\ Chongqing University of Education; Chong Qing; 400067 \\ hunter2011@foxmail.com
}

Keywords: Local undergraduate colleges; Student education management; Information transmission

\begin{abstract}
Good information transmission system can effectively improve the efficiency of school student education management, which can effectively carry out the transformation and development of the necessary protection. As the new local undergraduate colleges and universities have just entered the ordinary undergraduate course, the students still have a series of problems to be solved in the education management. The newly-built local undergraduate college students education management information transfer investigation analysis, we find that the newly-built local undergraduate colleges should focus on schools and students, schools and parents information channel expansion, and collaborative counselors and students, counselors and parent information channel, build "counselor" as its core, with school restructuring and development needs, students education management information transfer system, the work of transforming the school security.
\end{abstract}

\section{The Introduction of Background}

With the continuous development of information society, students, teachers and community information and services on campus are increasingly high requirements ${ }^{[1]}$. In June 2014, the State Council issued the "decision to accelerate the development of modern vocational education": full deployment of modern vocational education through demonstration lead, the pilot pushing etc., guide a group of ordinary colleges and universities to the application of technology-based institutions in transition development of. New Local University as a special participation in the restructuring and development group, to establish the necessary guarantees sound good education messaging system is the restructuring and development, and as a sub-system, an important part of the "student education management information delivery system," more can’t or missing ${ }^{[2]}$.

Chongqing University of Education is a so "rooted in Chongqing basic education, teacher professional development services" for the mission, by the Chongqing Municipal Education Commission in charge of public ordinary undergraduate school. Upgraded restructuring in 2012, has just entered the regular undergraduate sequence shortly, in all aspects of self-exploration stage, especially in terms of student education management information delivery, has some representation. Through a series of problems on the line for the school survey analysis to explore constructing a concrete, feasible, and effective student education management information delivery system, to provide the necessary reference for the Local Newly transformation in student education management information transfer terms ${ }^{[3]}$.

\section{The Research Methods}

Through various academic journals network data repository, and refer to books published in recent years, the application of non-structured qualitative analysis of logical reasoning. Chongqing University of Education visited the faculty teachers, students and parents collect their information transfer problem feedback and suggestions on issues related interview survey. With related information, management, communication, education and other theories, around student education management information transfer college concrete reality, a lot of research results have been screened, processing and analysis, transfer information from the body and System sight conduct assessment, deduce relatively objective and reasonable framework to protect the transmission of 
information and evaluation System ${ }^{[4]}$.

\section{The Survey Results}

Based on the literature analysis, combined with students, parents and teachers interview survey summarized. Currently, the new Local Colleges of Chongqing University of Education there is a problem in the transmission of information in the student's education management: First, do not build the digital campus information systems, information systems have been built or incomplete, non-standard, the school does not meet the actual situation, blind construction. In addition, the university campus network information platform underutilized, content deletion, failure to update the content, the lack of timeliness; cause can't find the latest inform students, teachers and parents in the school's official website as well as the required documents. Such as: Some colleges and universities was renamed after a period of time, a lot of files on the campus network, tables, media coverage, etc., are still using the previous name of the school or undergraduate colleges and universities have been upgraded, the network is still at the formulation and specialist work routine. ${ }^{[5]}$.

Secondly, the content of the notification format and file transfer mode is not standardized, the lack of the necessary official, serious, resulting in teachers and students do not care, do not pay attention, cause information loss in the transmission process, aliasing, alienation or even anti-oriented, seriously affecting work effectiveness. Mainly in the part of the information transfer body is not strong sense of responsibility, leading to lack of authoritative information, and even the loss of authority; frequent change of information as in the case did not check the authenticity of the information, or even contradictory information content around. In addition, the lack of information in the process of passing the necessary sense of responsibility and the necessary continuity, the same information is only as a baton pass out from their hands, after passing the integrity of the information is no longer involved, whether timeliness and timely information has been passed to reach receiving body.

Thirdly, the information pathway single, presence information covering blind spots and targeted, resulting in some teachers and students are unable to receive the latest real-time notification or document, affecting the normal working order. Mainly in the transmission of information subject populations IT literacy is not high, a considerable number of people unable to grasp the necessary campus network using technology, tend to stay in the general chat or receive a file, the file will not be passed without the use of office systems and services program, did not give full play to the campus network platform and other public functions. The above points are new established local university students in educational management widespread problem ${ }^{[6]}$.

Based on the new issues related to local universities Chongqing University of Education student education management information transmission Interview Survey feedback data, initially built up a student local newly education management information to deliver interactive flow diagram shown in Figure 1, the thickness of the arrows degree representatives of communication frequencies. Information interactive traffic order in descending order is shown in Table 1.

Table 1.The student education management information exchange transfer traffic rank

\begin{tabular}{|c|c|}
\hline Information exchange body & rank \\
\hline School counselors & 2 \\
\hline Students and counselors & 1 \\
\hline students and parents & 3 \\
\hline Schools and students & 4 \\
\hline Schools and parents & 5 \\
\hline
\end{tabular}

As the core of the entire student from counselor education management information delivery system, plays an important complementary role in bridge and effective communication between schools, parents, students, carrying important information is subject tripartite coordination. From Figure 1 and Table 1, we can see that communication aspects of the social dimension of the information presented single pass, interactive interaction insufficient presence, a lot of information 
is passed indirectly through counselors, increase information processing burden counselors, pending further counseling. Therefore, the school and the social dimension of the need for further expansion of the information channel capacity and interoperability in order to improve the timeliness of transmission of information, authority ${ }^{[7]}$.

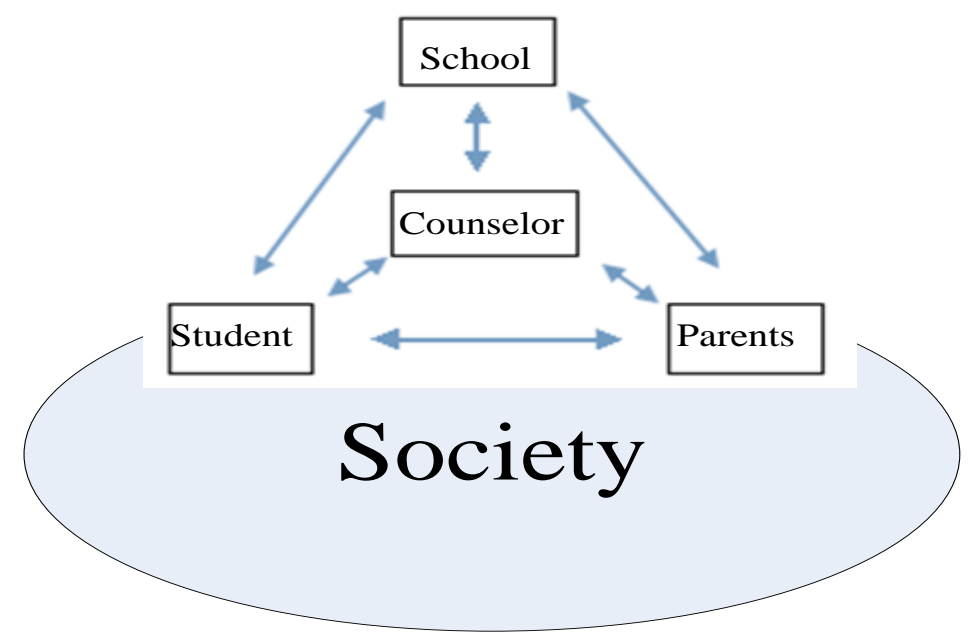

Fig. 1.The student education management information transfer flow

\section{The Education Management Information Relationship Analysis between Universities Transfer Body}

Daily Student Educational Management in Local Universities engaged in communication all the time, especially counselors, communication is particularly important. To communicate with superiors, communicate with students, but also communicate with parents and the community, it is the core of information transmission system. The main way student education management information passed is "communication." Good communication can make information communication body reach mutual understanding and trust both sides in the exchange of ideas and information. Communication is a way to make a unit that combines a variety of activities, and good communication can make our work toward the same goal, the same direction. In addition to physical communication, language exchanges, the two sides also exchanged emotional aspects, as well as other aspects of the impact and penetration behavior of the subject ${ }^{[8]}$.

The whole student education management information system, the most frequent is the most informative. Practice of ideological and political education, the college students and instructors to communicate effectively is an important way to carry out ideological and political education, ideological and political education is the premise and an important means to improve. Students communicate effectively with a counselor is reflected in the party's basic approach students give humane care and psychological counseling, as well as college students to cultivate self-esteem, rational calm, an important means of social psychology of positive, it is more to improve the effectiveness of ideological and political education important guarantee. It is important to communicate the overall counselors and college students on the front, there is poor communication between the minority phenomenon only; the impact of personal qualities counselor, charisma and school ethos style of study, education management system on the relationship between the two main large, and the relative impact of the conflict of interest, values; the two sides deal with conflict overall attitude is optimistic, positive, and a small number of students more negative attitude ${ }^{[9]}$.

Much daily management of contents college counselors were their daily work in the past. Rational communication with parents can better carry out the management of student education, counselors and parents to communicate is an important way to get the students' personality, character, strengths and other information. As student education management frontline workers, counselors must take the initiative to contact parents of students in communication with them, to communicate among our students get information so that we can vary to better carry out the subsequent student management. In addition, counselors communicate with parents can also make 
school education and family education exchange, mutual feedback information on student learning and life, "two-pronged" family education and school education to achieve coordination of scientific educational philosophy, students education management work achieve a multiplier effect, comprehensively promote the healthy development of students ${ }^{[10]}$.

Communication between schools and counselors are the "notice" the "Feedback" mode. School counselor transmission of information with a strong official, timeliness; and the transmission of information to the school counselor is already "feedback" based, with real-time, normative characteristics. School "notice" content format with a file transfer mode should be standardized, platform, open, in order to ensure its official nature, seriousness and timeliness. Counselor "feedback" organization and reporting of information content should be strictly in accordance with the provisions of the notification requirements, and strictly ensure timeliness and regulatory information. Implementation Specification only good "on the pass issued" in order to guarantee efficient transmission of information. Schools and parents, student information transfer is mainly manifested as unidirectional oriented, that parents or campus by campus official website official telephone and other related ways to parents and students to understand the basic information-based school, the school has passed out information universality, universality, lack the necessary relevance, specificity, but indirectly through the school counselor to make its information to students, parents pass targeted, specific.

\section{The Recommendations of Messaging Construction System}

The school is an important gateway to the campus Web site campus information to pass to the outside world, is based on the official establishment of the school network platform, bearing the important task of education outreach information age, education management, network teaching is the current trend of the development of distance education needs and the platform should be, campus official website understandable provide sharing of resources and so on campus teaching, research and management, information exchange and collaborative work computer network web system. In recent years, the rapid development of the campus Web site construction, major colleges and universities have built their own independent domain name of the site; however, the website information is updated in serious lag in local universities, and website maintenance deficiencies, good information platform has not been effective It uses. Therefore, local colleges should strengthen information platform for building and maintenance, to establish timeliness, openness and strong campus information window, campus service management, service school education and teaching, improve school social effects ${ }^{[11]}$.

Notification files, also known as normative documents, is a normative behavioral attributes and constraints content collection agencies at all levels of the various documents issued by the most common type. China's laws and regulations in terms of meaning and significance of the notification documents, production and publishing body, procedures and authority and the review mechanism is no standardized, comprehensive description, but in some areas to explore to achieve a normative document made uniform, uniform numbers, unified management "three reunification", the initial realization of the standardized management of normative documents. Universities as institutions, which notice shall have the necessary official necessary, seriousness, in order to achieve efficient transmission of information and the spread.

News information refers to all the content of human social communication. Transport and communications systems are handled by this object; specific information about its specific receptors, by obtaining, identifying different information, and the fastest speed information is transmitted to the corresponding receptor (specific groups or individuals). Therefore, the information in the pathway should have diversity, multidimensional, the first time in order to ensure that the information is transmitted to a specific population or individual, to prevent information covering blind spots. For students and counselors, schools and counselors, parents and counselors should have a diversity of information channels, building telephone, Internet, face to face, multi-dimensional communication system, prevent information transfer interrupt, information covering issues such as busy spot ${ }^{[12]}$. 


\section{Conclusions}

Information channel is connected to the main body and information source information space agency, after processing information dissemination sector information diffusion only goes through smooth information channel to spread to target the body, so that information generating value and effectiveness. Local Newly shunt should be noted that the flow of information, focusing on direct information exchange between schools and students, schools and parents, counselors mitigate information processing pressure to ensure the timeliness of transmission of information, authority. Collaborative counselors and students, counselors and parents two information transmission channels and build efficient education management information delivery system on campus.

\section{Acknowledgements}

Funded projects: Chongqing Municipal Education Commission, Humanities and Social Sciences funded projects merit (Code: fdyzy2015009)

\section{References}

[1] Y. Wang. wisdom campus overall architecture model and typical applications. China Educational Technology, 2014, 09: 88-92 + 99.

[2] X. Xia, S. Zhao. innovative research under the new situation Student Management Model. China Adult Education, 2014, 15: 35-37.

[3] P.B. Yang ..Human society and the social contract - Based on Social Exchange Theory. Social Sciences, 2011, 09: 67-75.

[4] Y. Shen. College students to communicate effectively with a counselor psychological demands and achieve path.college counselors, 2013, 06: 16-19.

[5] X. Li. Ping effective communication college counselors and college students. Nanjing Normal University, 2012: 24-26.

[6] F.J. Wang, S.H. Lu. research on the application of comprehensive communication model student management work. Education, 2011,03: 81-83.

[7] HAN rain Discussion on school education and family education combining. Changchun Institute of Education, 2011, 10: 20-21.

[8] Cheng crystallization money Xiaofang, Zhang Fang Personalized Information Service under the Network Environment Approach to, Modern intelligence, 2011, 09: 62-66 + 79.

[9] C. Zhang, L.J. Li. Google Analytics in campus site data analysis. Modern Educational Technology, 2013, 09: 52-55 + 51 .

[10]X.X. Wang. Problems and Solutions Network Culture Construction of College Campus faced. China Adult Education, 2013, 23: 68-70.

[11] Specification document class characteristics of Yang Rong. archives communications, 2008, 06: 33-38.

[12] Yang taught information defining aspect record on the definition of research in information analysis and commentary. Information Science, 1986,04: 43-61. 